\section{CLIMATE AND INSECT LIFE}

\section{By Dr. C. B. WILLIAMS}

Rothamsted Experimental Station

$\mathrm{T}$ HE problem of the relation of insect life to climate and weather conditions has always attracted naturalists, both from its scientific and its practical importance; but most of the early work was qualitative rather than quantitative and, owing to the complexity of the problem, little real progress was made. Here and there, however, some of the results were expressed in the form of general laws, such as the 'hyperbola' relation between temperatures and length of development, and Hopkins' 'bio-climatic laws' relating to the dates of occurrence of biological events, including the outbreaks of certain insects.

In 1929, the Conference of Empire Meteorologists in London pressed for the extension of such studies; and in 1931 Uvarov produced an excellent survey of the literature to that date-which is (partly as a tribute to its own value) now out of date owing to the progress of the last fifteen years.

At a joint meeting of the Royal Meteorological Society and the Royal Entomological Society held in London on June 20, papers were read on various aspects of the problem, and emphasis was laid on the urgent need for more work and more co-operation between entomologists and meteorologists if rapid progress is to be made.

The effect of climate and weather conditions on insects is of course only one particular part of the wider study of bio-climaties, but it is worthy of separate consideration in view of the enormous number of species of insects, the possibilities that they have for very rapid changes in numbers, and their great economic importance as pests and as carriers of disease.

There are certainly more than one million different species of insects in the world-more than all other kinds of animals and plants together-and each is subject to the effect of weather and climate from the moment that the egg is laid, through the various stages of metamorphosis, to maturity and death. Each is affected in speed of development, in fertility, and in length of life; and, as these three factors combined determine the rate of multiplication, climate and weather conditions are the major part of the study of insect populations and hence of insect outbreaks or epidemiology.

The permanent existence of an insect in any area depends in general on the 'climate', or average weather conditions of that area. Its variations in numbers in any locality are due to the variations in climatic con- ditions from day to day or from year to year that we call 'weather'. Even the movement of insects, passive or active, short flights, or longdistance migrations, are at all times at the mercy of weather conditions: and when any particular insect is not affected directly, it may easily be affected indirectly through the effect on its natural enemies or its food supply.

Turning to the meteorological factors involved, we find conditions of equal variety and complexity. What we call 'weather' is the summation of change in a number of separate factors: temperature, humidity, pressure, light, etc. Under temperature we have to consider the average air-, water- or soiltemperatures; also its daily and seasonal variation, average maximum, average minimum, and also extreme maximum and minimum. An occasional frost, once only in several years, may have an enormous effect on the insect population; and tropical conditions are determined almost as much by the absence of low temperatures as by the presence of a high average. The question of radiant heat is also involved. Water can take the form of rainfall (the seasonal distribution of which is at least of as great importance as the total amount), air humidity, cloud (affecting radiation from the sun during the day and from the earth at night), dew, soil moisture and so on. Wind and air movements affect evaporation from both plants and insects. Barometric pressure, and the number of hours of daylight or sunshine also have complex direct and indirect results.

To add to the complexity, insects, as opposed to plants, have powers of movement which enable them, within perhaps only a few feet, to exert a choice among a variety of microclimates and so to avoid dangerous extremes. In fact, we have the two great

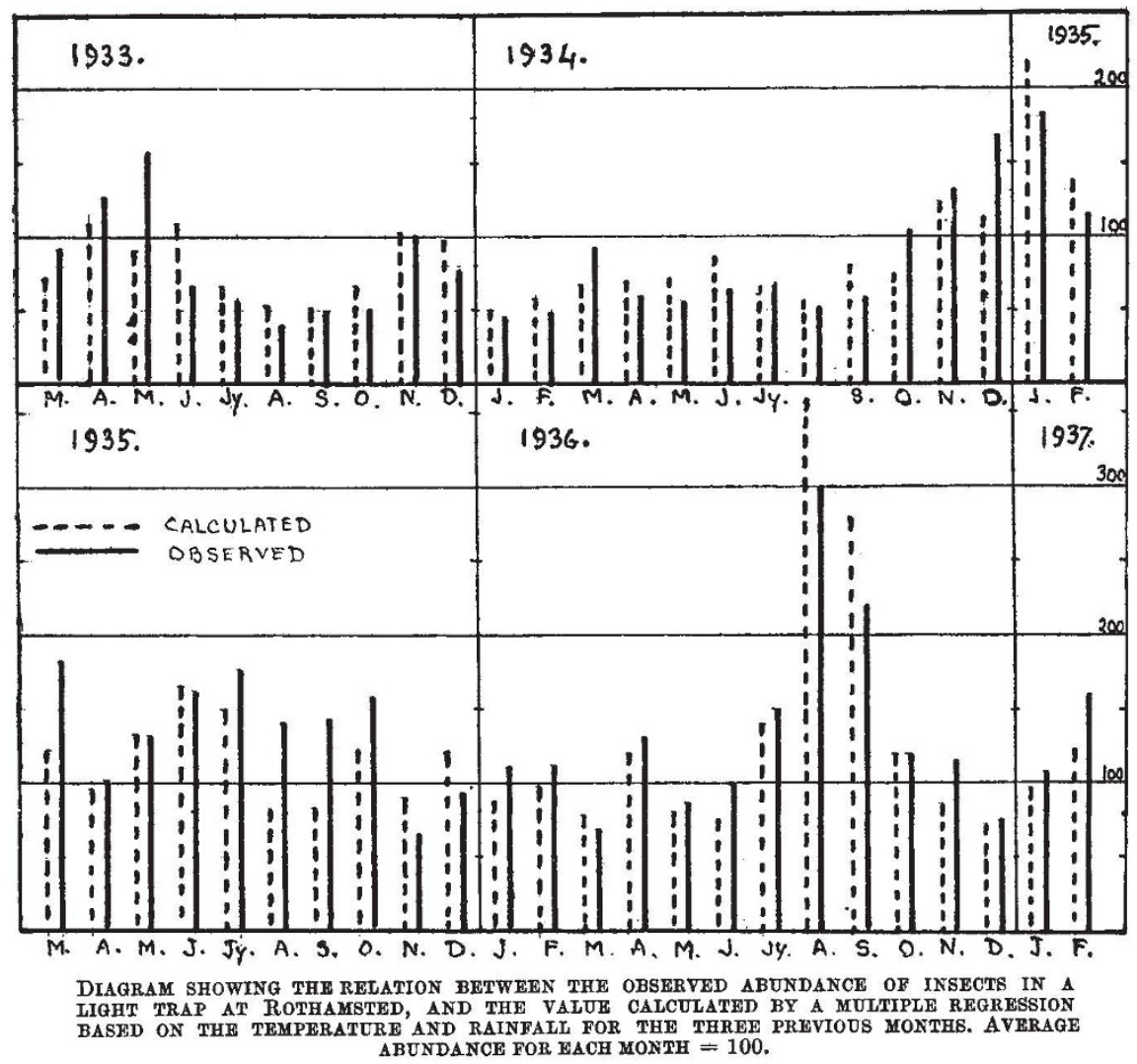


complexes of insect variety on one hand and climatic variety on the other; and the task of analysis and synthesis of their inter-relations is almost Herculean.

Until recently, meteorologists had the advantage in that most of their factors could be easily expressed numerically as measurements and so lent themselves to mathematical treatment. It is one of the main tasks of the entomologist in the near future to convert as many as possible of his observations into measurements. The day has come when expressions of the type "not quite so common" or "rather more abundant" must be replaced by terms comparable in accuracy to the meteorological records with which we wish to correlate them. But the task is by no means easy, and many experiments and many mistakes will have to be made before anything like success can be achieved.

It is interesting to speculate as to whether there is more hope of progress by analysing and simplifying the problem into its component parts in controlled laboratory experiments; or by tackling the whole complex of observations in the field! In this connexion it may be noted that the whole tendency of field experiments in agriculture in the last twenty-four years has been away from extreme simplification, and towards greater complexity. It has been found that, if sufficient facts are available, the complex data can be analysed by statistical methods, and more information can be obtained in a shorter period, particularly on the problem of inter-relations of one factor with another, which are eliminated by extreme simplification.

Undoubtedly more progress has been made in the past by studies under laboratory conditions, but the application of the laws and principles so discovered back again to problems in the field has been disappointing.

My own feeling is that-whatever the difficultieswe must study the insects so far as possible in the field under natural conditions; and experiments and field observations were started at Rothamsted about ten years ago with this in view. A standardized light trap was put out into one position in a field and was used to catch insects for more than 1,400 consecutive nights in four years. The number of insects captured each night was used as a basis for correlation with miteorological factors. The field observations were unfortunately brought to an end by the War, but from the thousands of figures already obtained we have been able to get measurements of the effect of most of the principal meteorological factors both singly and in combination with others. Finally, we have been able to forecast the general level of insect abundance from the weather conditions of the previous months. As an example of this, the accompanying diagram shows the correspondence between observed and calculated abundance of insects at Rothamsted for forty-eight consecutive months; the calculated figures being based on two multiple regression formulæ, one for the winter months, and one for the summer. The mathematical analysis showed that, under the climatic conditions of the area, rainfall is the determining factor of insect abundance in the summer, and temperature in the winter; a result which is obviously sound in a district where the rainfall is more or less constant throughout the year while the temperature varies from low in winter to high in summer.

But, of course, the problem must be attacked from all sides and progress will be made from all directions, if only accuracy of measurement can be brought into the biological side. The problem is essentially a mathematical one, and the accuracy of the results will depend on the absence of vagueness in the original observations.

The joint meeting of the Royal Meteorological Society and the Royal Entomological Society, after hearing short papers by Major H. C. Gunton, Dr. C. B. Williams, Dr. A. E. Slater and Dr. B. P. Uvarov, and an interesting general discussion, passed resolutions emphasizing the need for more bio-climatic work on insects and the need for further training of economic entomologists in the principles of meteorology. It was also suggested that other biological societies should take some share in responsibility for the production of the annual Phenological Report, at present sponsored entirely by the Royal Meteorological Society.

\section{WEATHER AND ELECTRIC POWER SYSTEMS}

$\mathrm{A}$ JOINT meeting of the Institution of Electrical Engineers and the Royal Meteorological Society was held on October 18 to discuss the effects of weather on electric power supply systems.

The meeting was opened by four short papers, two by Mr. J. S. Forrest and Mr. H. W. Grimmitt presenting the subject from the point of view of the electrical engineer, and two by Mr. A. J. Drummond and WingCommander R. M. Poulter describing the meteorological point of view. In the ensuing general discussion, the following speakers took part: Mr. C. K. M. Douglas, Mr. R. A. S. Thwaites, Dr. J. Glasspoole, Mr. E. B. Powell, Mr. E. G. Dymond, Mr. G. Manley, Mr. C. G. Carrothers, Mr. J. F. Shipley, Mr. E. E. Hutchings, Mr. W. Hill, Mr. C. T. Melling, Mr. W. N. C. Clinch, Mr. P. Schiller, and Mr. G. W. N. Cobbold.

In the course of the meeting, a demonstration was given of the radio-sonde, and other meteorological instruments operating on electrical principles. The main features of the discussion are summarized here.

In general, weather affects power systems in two ways : it causes variations in the load on the plant, and it may, under abnormal conditions, cause actual damage to equipment and an interrupticn of supply.

\section{Load Variations Due to Weather}

The lighting load is mainly a function of the daylight illumination, while the heating load is deter. mined largely by the air temperature, and, to a lesser extent, by the wind velocity and relative humidity. The heating load requires serious consideration as it may amount to a significant proportion of the total load. For example, in the case of the south-east England electricity supply system, the peak load on two winter days, only a week apart, was found to differ by 22 per cent, which was $400,000 \mathrm{~kW}$., owing to a drop of $25^{\circ} \mathrm{F}$. in the mean air temperature.

Many supply engineers have derived empirical relationships between load and temperature, and between load and daylight illumination. In this way, they are able to predict, within a few per cent, the effect which changes in temperature or illumination will have on the load. In addition, three-dimensional models have been prepared in order to study the correlation between load, temperature, and illumination. There is, however, scope for further work on this subject. 